\title{
Potential of megathrust earthquakes along the southern Ryukyu Trench inferred from GNSS data
}

Masayuki Kano ${ }^{1 *}$ (D) Aoi Ikeuchi ${ }^{1}$, Takuya Nishimura² ${ }^{2}$ Shin'ichi Miyazaki ${ }^{3}$ and Takeshi Matsushima ${ }^{4}$

\begin{abstract}
The southern part of the Ryukyu subduction zone has recorded tsunami events with a recurrence interval of several hundred years. Although their source is controversial, one model suggests that the last 1771 Yaeyama tsunami was caused by a shallow megathrust earthquake with a magnitude of 8 . However, the current knowledge on interplate coupling based on recent geodetic data is limited. Here, a time series of Global Navigation Satellite System data from January 2010 to February 2021 was analyzed, including newly installed stations by Kyoto and Kyushu Universities, to obtain the distance changes between stations and vertical secular velocities. The distance changes ranged from $2.4 \mathrm{~mm} /$ year in contraction and to $4.7 \mathrm{~mm} /$ year in extension, and the vertical velocities exhibited no clear uplift or subsidence, with - 2.4 to $1.1 \mathrm{~mm} /$ year. The back slip inversion results indicated a slip deficit of $17-47 \mathrm{~mm} /$ year to the south of the Yaeyama Islands. The large slip deficit area is complementarily intervened between the shallower source area of low-frequency earthquakes and the deeper slow slip region, suggesting the spatial heterogeneity of frictional properties along the plate interface. If the large slip deficit area accumulates stress in the same rate since the last 1771 earthquake, it could result in a megathrust event with a moment magnitude greater than 7.5. Because the limited onshore data cannot resolve the slip deficit on the shallow plate interface, seafloor geodetic observations are essential to clarify the detailed spatial distribution of the slip deficit and discuss its earthquake and tsunami potential.
\end{abstract}

Keywords: Ryukyu subduction zone, GNSS, Interplate coupling, Slow slip events, Low-frequency earthquakes

\footnotetext{
*Correspondence: masayuki.kano.a3@tohoku.ac.jp

${ }^{1}$ Graduate School of Science, Tohoku University, 6-3, Aramaki-aza-aoba,

Aoba-ku, Sendai 980-8578, Japan

Full list of author information is available at the end of the article
}

\section{Springer Open}

(c) The Author(s) 2021. Open Access This article is licensed under a Creative Commons Attribution 4.0 International License, which permits use, sharing, adaptation, distribution and reproduction in any medium or format, as long as you give appropriate credit to the original author(s) and the source, provide a link to the Creative Commons licence, and indicate if changes were made. The images or other third party material in this article are included in the article's Creative Commons licence, unless indicated otherwise in a credit line to the material. If material is not included in the article's Creative Commons licence and your intended use is not permitted by statutory regulation or exceeds the permitted use, you will need to obtain permission directly from the copyright holder. To view a copy of this licence, visit http://creativecommons.org/licenses/by/4.0/. 


\section{Graphical Abstract}

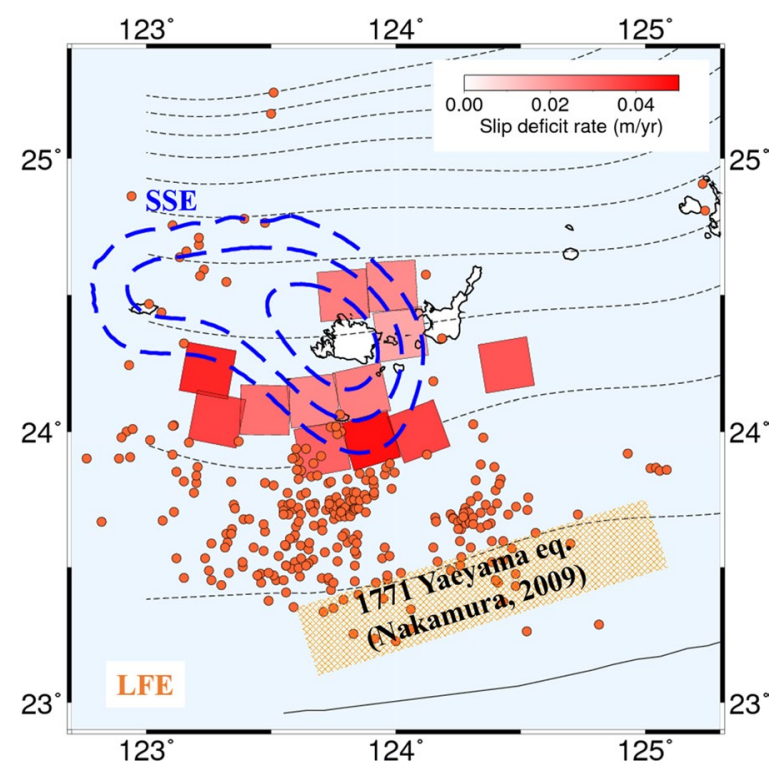

\section{Introduction}

The Yaeyama Islands (which is the generic collective term for this group of islands) are located in the extreme southwestern part of Japan, situated on the Ryukyu Arc (Fig. 1a). This is the zone where the Philippine Sea plate $(\mathrm{PH})$ is subducting northwestward along the Ryukyu Trench at a rate of 8.0-8.5 cm/year relative to the South China block (Sella et al. 2002). In addition, back-arc spreading occurs along the Okinawa Trough to the north of the islands (Sibuet et al. 1998) at a rate of $3.5-5.0 \mathrm{~cm} /$ year (Nishimura et al. 2004). Therefore, the plate convergence rate of $12.0-13.0 \mathrm{~cm} /$ year in this region, relative to the $\mathrm{PH}$, is considered to be fast.

Along the subducting PH interface, various types of fault slips with different time constants have been documented. Based on Global Navigation Satellite System (GNSS) observations, slow slip events (SSEs), slow fault slips that last for approximately 1 month, have been recurrently located at $\sim 25$ to $40 \mathrm{~km}$ depths beneath the northwestern part of Iriomote Island (Fig. 1a) (Heki and Kataoka 2008; Nishimura 2014; Tu and Heki 2017). These SSEs occur approximately every 6 months with a moment magnitude (Mw) of 6.6-6.7 (Kano et al. 2018b). Kano et al. (2018b) investigated the slip history at the plate interface for $\sim 2.5$ years, including five SSEs. They estimated an average slip rate of $\sim 13 \mathrm{~cm} /$ year at the large slip area of SSEs by dividing the total slip for the five SSEs by the analysis period, including both SSE and inter-SSE periods. This average slip rate is comparable to the relative plate motion, indicating that the main slip area is entirely coupled during the inter-SSE period and the SSEs release most of the accumulated strain (Kano et al. 2018 b). On the shallower side of the SSE region at depths of $\sim 10$ to $20 \mathrm{~km}$, the seismic signatures of slow fault slips with dominant frequencies of a few $\mathrm{Hz}$ and a few tens of seconds, known as low-frequency earthquakes (LFEs) and very low-frequency earthquakes (VLFEs), have often been identified (Fig. 1a) (Ando et al. 2012; Nakamura and Sunagawa 2015; Arai et al. 2016; Nakamura 2017). The magnitudes of LFEs and VLFEs were estimated to be 2.8-3.4 and 3.4-4.8, respectively (Nakamura and Sunagawa 2015; Nakamura 2017). For the shallowest part of the plate interface, Nakamura (2009) indicated the possibility of the occurrence of the 1771 Yaeyama earthquake close to the Ryukyu Trench (Fig. 1a). He demonstrated that a shallow thrust-type fault model with an Mw of 8.0 could reproduce the tsunami height records observed at the Yaeyama Islands. In addition, tsunami deposits that recorded four tsunami events with a recurrence interval of $\sim 600$ years supported this shallow fault model (Ando et al. 2018). Based on the slip amount of the source model in Nakamura (2009), the plate convergence rate, and the recurrence interval of earthquakes, the seismic coupling ratio in the region was estimated to be $\sim 20 \%$ (Ando et al. 2018). Moreover, geodetic analysis indicated low interplate coupling near the trench region. Watanabe and Tabei (2004) analyzed GNSS velocity data for 1996-1999. Due to sparse GNSS stations, they combined GNSS data with moment tensor data of shallow earthquakes to increase the spatial resolution at shallow depths and 

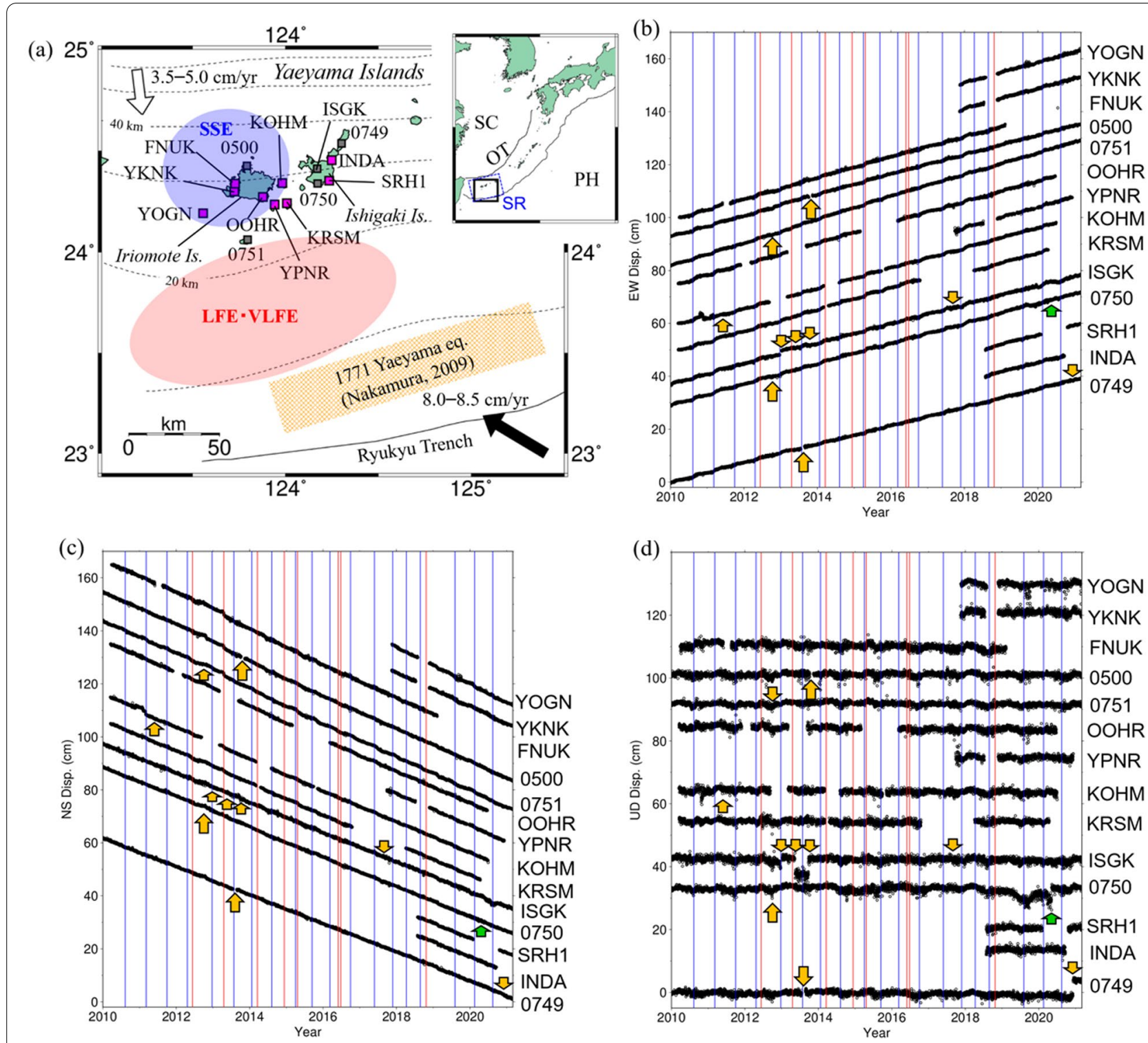

Fig. 1 Tectonic setting and GNSS time series. a Study area. The black rectangle in the inset is the location of the Yaeyama Islands where the Philippine Sea plate (PH) is subducting beneath the islands at a rate of $8.0-8.5 \mathrm{~cm} /$ year relative to the South China block (SC) (Sella et al. 2002). The Yaeyama Islands are considered to be located on the South Ryukyu block (SR), which are roughly indicated by the dotted blue rectangle (Nishimura et al. 2004). The squares are the locations of the GNSS stations with four-digit station codes. The purple squares indicate the stations newly installed after 2010. The red-, blue-, and orange-colored regions correspond to the source areas of slow slip events (SSEs) (Heki and Kataoka 2008), low-frequency earthquakes (LFEs) (Arai et al. 2016; Nakamura 2017), and the estimated source area of the 1771 Yaeyama earthquake (Nakamura 2009). The white arrow represents the motion of the back-arc spreading of the Okinawa Trough (OT) (Nishimura et al. 2004). The location of OT is indicated in the inset. The solid and dashed lines are the Ryukyu Trench and the depth contours of the upper surface of the subducting PH with an interval of $10 \mathrm{~km}$ (Slab 2) (Hayes et al. 2018). b-d GNSS time series sorted from westernmost (top) to easternmost (bottom) stations in b east-west, c north-south, and $\mathbf{d}$ up-down components. The red and blue vertical lines represent the timings of earthquakes considered in this study and the occurrence of SSEs. The timings of SSEs were determined by Tu and Heki (2017) before 2016 and by visual inspection after 2017. The orange arrows indicate the timings of antenna replacements, and green arrows indicate an unknown offset appearing in the up-down component, which was eliminated in estimating velocities. GNSS Global Navigation Satellite System

suggested that interplate coupling close to the trench in the analysis period was $<10 \%$. Nevertheless, the source region of the 1771 Yaeyama earthquake and related tsunami is still under debate, with proposed mechanisms of a megathrust tsunamigenic earthquake (Nakamura 2009), an intraplate earthquake with a submarine 
landslide (Imamura et al. 2008), an earthquake along a splay fault (Hsu et al. 2013), and the collapse of an accretionary prism near the trench (Okamura et al. 2018), as summarized in Fujiwara et al. (2020).

For further understanding of the interplate coupling along the southern Ryukyu subduction zone, additional GNSS stations were installed in the 2010s on the Yaeyama Islands (Fig. 1a). Stable estimation of secular velocities and distance changes between stations is currently possible due to the continuous acquisition of data. Therefore, this study estimates the spatial distribution of the slip deficit rate (SDR) and discusses the possibility of a megathrust event in the southern Ryukyu region.

\section{Secular velocities and distance changes between GNSS stations on the Yaeyama Islands}

The GNSS daily coordinates were analyzed to estimate the secular velocities at 14 GNSS stations deployed on the Yaeyama Islands (Fig. 1a). The GNSS stations consist of four permanent GNSS Earth Observation Network System (GEONET) stations (0500, 0749, 0750, and 0751) operated by the Geospatial Information Authority of Japan (GSI), six stations (FNUK, INDA, KOHM, KRSM, OOHR, and SRH1) operated by Kyoto University (KT), three stations (YKNK, YOGN, and YPNR) operated by Kyushu University (KS), and one station (ISGK) operated by the National Astronomical Observatory of Japan (NAO). All GEONET stations have been operational since the 1990s, and the NAO station was installed in 2002. In addition to these stations, four of the KT stations (FNUK, KOHM, KRSM, and OOHR) were established in 2010, which contributed to improving the spatial resolution for monitoring SSEs beneath the islands (Kano et al. $2018 \mathrm{~b})$. The remaining five $\mathrm{KT}$ and $\mathrm{KS}$ stations were established in 2017 or 2018 . Through the installation of these new KT and KS stations (highlighted by purple squares in Fig. 1a), we expected to improve the spatial resolution for monitoring the crustal deformation on the Yaeyama Islands, especially across the western parts. The
GNSS data from January 2010 to February 2021 were preprocessed by the Gipsy-X ver1.3/1.4 software to obtain the time series of daily coordinates. The VMF1 mapping function (Boehm et al. 2006) and FES2014b model (Lyard et al. 2021) were used for tropospheric delay modeling and correction of ocean tide loading, respectively. The precise ephemerides and translational parameters of coordinates into the International Terrestrial Reference Frame (ITRF) 2014 coordinate system were provided by the Jet Propulsion Laboratory. Finally, the coordinates were converted to east-west (EW), north-south (NS), and up-down (UD) components (Fig. 1b-d). We used all data from the period from January 2010 to February 2021 at each site to estimate the secular velocities in the following analysis.

The secular velocity of each component at each GNSS station was estimated using the est_noise software (Langbein 2017), which assumes a temporal correlation for modeling observation noise. Here, the noise model was adopted in combination with white noise, flicker noise, random-walk noise, and bandpass-filtered noise of $0.5-2$ cycles/year with three poles, to maximize a likelihood function (Langbein 2004). The analysis modeled offsets due to antenna replacements, relocation of the antenna to the nearby building, or earthquakes, and apparent offsets with unclear origin (Fig. 1). Here, we considered earthquakes with larger $(>6.0)$ magnitude in the unified hypocenter catalog provided by the Japan Meteorological Agency (JMA) that occurred close to the Yaeyama Islands (Table 1, Fig. 1 and Additional file 1: Fig. S1). The obtained secular velocities in the horizontal direction exhibited a south-southeastward motion of $63.9-80.2 \mathrm{~mm} /$ year with a maximum error of $\sim 3.1 \mathrm{~mm} /$ year in the ITRF 2014 (Fig. 2a). On the other hand, vertical velocities were estimated to range approximately from -2.4 to $1.1 \mathrm{~mm} /$ year with errors ranging from $\sim 0.5$ to $2.5 \mathrm{~mm} /$ year, thereby exhibiting no clear uplift or subsidence (Fig. 2c). We also estimated the secular velocities from January 2015 to February 2021 (Additional file 1:

Table 1 List of earthquakes considered in the analysis of the GNSS data

\begin{tabular}{llllllrr}
\hline & Year & Month & Day & Lon & Lat & Dep (km) & Mw \\
\hline$\# 1$ & 2012 & 6 & 10 & 122.267 & 24.417 & 70 & 0 \\
$\# 2$ & 2013 & 4 & 18 & 123.454 & 25.002 & 6.0 \\
$\# 3$ & 2014 & 3 & 19 & 122.283 & 23.937 & 21 & 6.1 \\
$\# 4$ & 2014 & 12 & 11 & 122.454 & 25.440 & 250 & 6.0 \\
$\# 5$ & 2015 & 4 & 20 & 122.427 & 23.956 & 6.1 \\
$\# 6$ & 2016 & 5 & 24 & 122.510 & 25.450 & 236 & 6.8 \\
$\# 7$ & 2016 & 6 & 23 & 123.332 & 23.497 & 6.2 \\
$\# 8$ & 2018 & 10 & & 12.596 & 23.955 & 6.2 \\
\hline
\end{tabular}




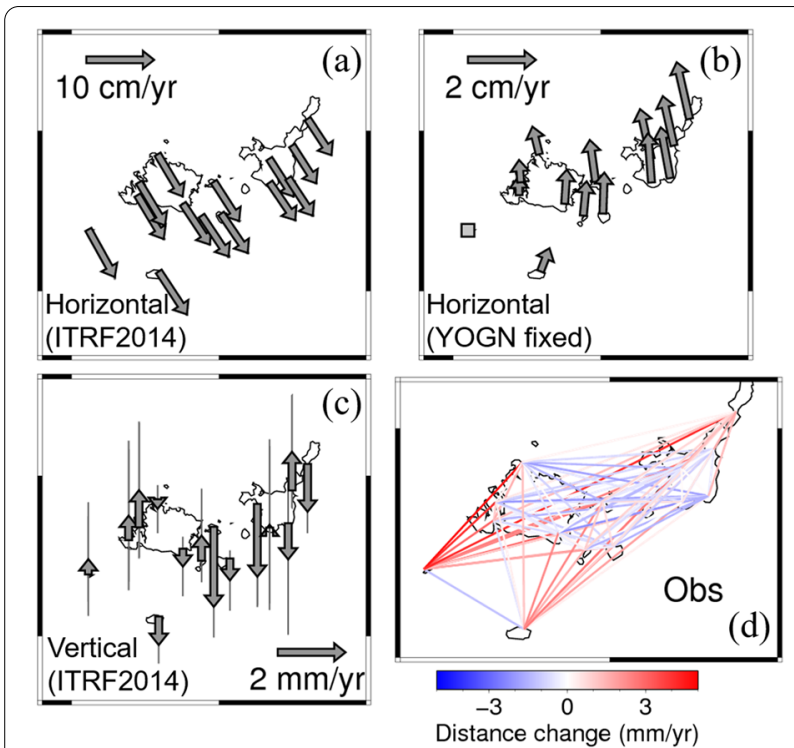

Fig. 2 Secular velocities and distance changes estimated from GNSS observations. a Horizontal component of the secular velocities in the ITRF2014. The $1-\sigma$ error ellipsoids are indicated, which are small compared to the velocities in the horizontal components. $\mathbf{b}$ Horizontal velocities relative to the westernmost station, YOGN. c Vertical component of secular velocities with $1-\sigma$ error bars in the ITRF2014. Note that the station locations are slightly moved to the horizontal direction for visibility reasons. $\mathbf{d}$ Distance changes between each pair of GNSS stations

Fig. S2), resulting in a difference in secular velocities of $<1.4 \mathrm{~mm} /$ year and $<2.8 \mathrm{~mm} /$ year in horizontal and vertical components, respectively. However, this difference did not affect the location of the large SDR region and the amplitudes shown in the following sections (Fig. 3 and Additional file 1: Fig. S3). Since this study focuses on long-term average crustal movements, we did not model the occurrence of SSEs (although signals of SSEs were repeatedly observed). This means that the secular velocities estimated here include the effects of stress release during the SSE period as well as stress accumulation during the inter-SSE period.

The obtained secular velocities were assumed to be composed of the combined effect of the rigid motion of the South Ryukyu (SR) block, where the Yaeyama Islands are located, and that of interplate coupling, if existing. To eliminate the effect of rigid block motion, the horizontal secular velocities were converted to the distance changes between each pair of stations. As a result, the distance changes ranged from $2.4 \mathrm{~mm} /$ year for maximum contraction to $4.7 \mathrm{~mm} /$ year for maximum extension. The distances in the direction from east-west to northwest-southeast showed systematical contraction, and those in the direction from northeast-southwest showed extension (Fig. 2d). The former was roughly parallel to the direction of plate convergence and implied interplate coupling. We used distance changes and vertical secular velocities in the following inversion analysis.

\section{Inversion analysis}

Assuming that the distance changes and the vertical secular velocities can be caused by interplate coupling, we conducted inversion to estimate SDR by implementing the backslip model (Savage 1983) in the following procedure. The plate interface of the subducting $\mathrm{PH}$ was modeled using the plate geometry of Slab 2 (Hayes et al. 2018) with planar subfaults (Fig. 3a). The entire region was divided into $9 \times 10$ subfaults in the strike and dip directions, respectively. The size of each subfault was $20 \times 20 \mathrm{~km}^{2}$ when the subfault was projected on the surface. We tested additional cases with a fault discretization of $15 \times 15 \mathrm{~km}^{2}$ and $10 \times 10 \mathrm{~km}^{2}$ subfaults and found that this fault discretization did not affect the main results (Additional file 1: Fig. S4). The surface response due to the fault slip rate in each subfault was calculated assuming a homogeneous elastic half-space (Okada 1992). The slip direction in each subfault was fixed to N45W, which is the approximately parallel direction to that of the subduction of the $\mathrm{PH}$ relative to the SR (Sella et al. 2002; Nishimura et al. 2004). We constrained non-negative fault slips and assumed zero fault slip in the additional subfaults surrounding the entire fault region, which are not explicitly represented in each figure, except for Fig. 3a. The smoothness constraint of the SDR in the neighboring subfaults was introduced to stabilize the inversion. Inversion was conducted to minimize the following cost function $s(\mathbf{m})$ :

$$
\begin{aligned}
& s(\mathbf{m})=(\mathbf{d}-\mathbf{G m})^{\mathrm{T}} \mathbf{E}^{-1}(\mathbf{d}-\mathbf{G m})+\alpha^{2} \mathbf{m}^{\mathrm{T}} \mathbf{L} \mathbf{m}, \\
& \mathbf{C}=\frac{s(\hat{\mathbf{m}})}{(N+P-M)}\left(\mathbf{G}^{\mathrm{T}} \mathbf{E}^{-1} \mathbf{G}+\alpha^{2} \mathbf{L}\right)^{-1},
\end{aligned}
$$

where $\mathbf{d}$ is the $N$-dimensional observed vector containing the distance changes and the vertical velocities, $\mathbf{G}$ is a matrix consisting of an elastic response on the ground surface, $\mathbf{m}$ is the $M$-dimensional model parameter vector including the amounts of SDR, $\mathbf{E}$ is the observation error covariance matrix, and $\mathbf{L}$ indicates a Laplacian matrix having a rank of $P$. In this calculation, the cost function $s(\mathbf{m})$ monotonically decreases with an increasing value of hyperparameter $\alpha^{2}$ in our problem, and thus, the hyperparameter $\left(\alpha^{2}=200\right)$ is adopted when the changing rate of a value in the cost function is small (Additional file 1: Fig. S5). The estimation error of the SDR is calculated from the corresponding diagonal element of the error covariance matrix $\mathbf{C}$ using the optimum parameter vector $\hat{\mathbf{m}}$ 


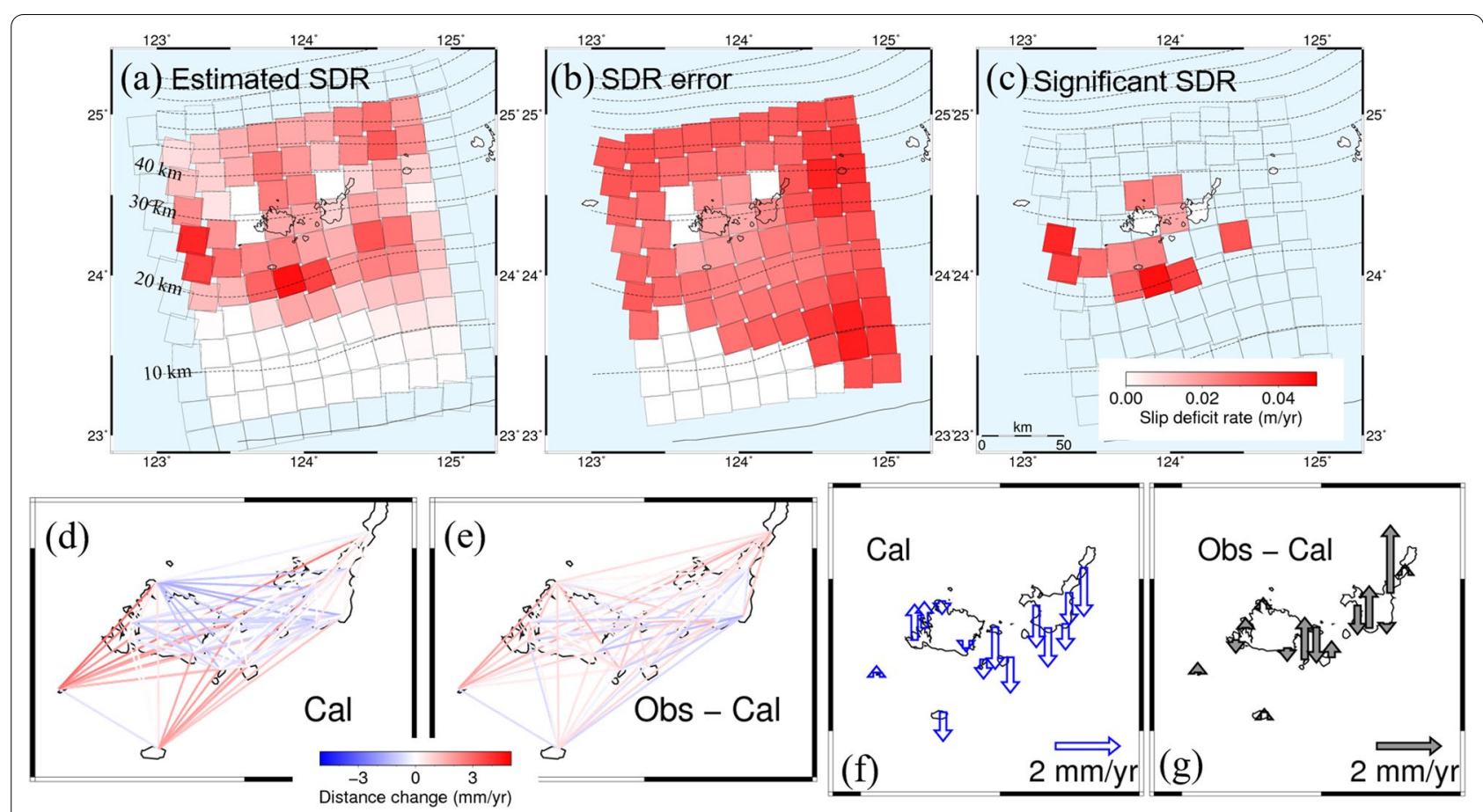

Fig. 3 Estimation of slip deficit rates (SDR) and comparison with observations. a Spatial distribution of SDRs and $\mathbf{b}$ their estimation error. c Same as a but only for subfaults whose SDR is greater than the estimation error shown. Note that the additional subfaults imposing zero SDR are shown only in $\mathbf{a}$. The solid and dashed lines are the Ryukyu Trench and the depth contours of the upper surface of the subducting PH with an interval of $10 \mathrm{~km}$ (Slab 2) (Hayes et al. 2018). d Calculated distance changes and e residual distance changes. $\mathbf{f}$ Calculated and $\mathbf{g}$ residual vertical velocities

\section{Spatial distribution of slip deficit rate}

The inversion results indicated a SDR distribution in a wide area of the fault region, with a value of up to $47 \mathrm{~mm} /$ year to the south of Iriomote Island (Fig. 3a). The SDR distributions reproduced the observed distance changes and the vertical secular velocities well (Fig. $3 \mathrm{~d}-\mathrm{g}$ ). However, their estimation errors were large as well, ranging from 17 to $45 \mathrm{~mm} /$ year (Fig. 3b), which were comparable or larger than the SDR, especially in the deep or eastern subfaults as well as the shallow subfaults. Therefore, hereafter, we discuss only the subfaults that had SDRs larger than their errors (Fig. 3c). The SDRs in these subfaults contributed to $56 \%$ of the residual reduction compared to the value calculated using the whole subfaults. Vertical velocities and distance changes calculated due to these subfaults (Additional file 1: Fig. S6) showed a similar spatial pattern compared to those due to the whole subfaults (Fig. 3d, f). However, there were differences between these calculated vertical displacements at stations located on the eastern and western side of the network, resulting in a worse fitting to the observation if we only considered selected subfaults. Similarly, the distance changes showing northwest-southeast contraction resulted in overestimation. This indicates that SDRs of deep subfaults smaller than the estimation errors would be necessary to further explain the data. However, it is difficult to show a significant existence of deep SDRs from the limited observations.

To investigate the robustness of the results, we conducted five synthetic tests assuming the SDRs in a checkerboard pattern (Additional file 1: Fig. S7), in a single region where large SDRs were estimated (Additional file 1: Fig. S8), or in shallow subfaults (Additional file 1: Fig. S9), as summarized in Additional file 1: Text S1. The checkerboard test indicated that SDRs deeper than $\sim 20 \mathrm{~km}$ were well resolved, while those at shallower depths $(<15 \mathrm{~km})$ were not (Additional file 1: Fig. S7). The locations of deep large SDR subfaults were not biased (Additional file 1: Fig. S8), although the smoothing constraint resulted in smoothed SDR distributions. On the other hand, the SDRs assumed at shallower depths were estimated to be deeper than their true location (Additional file 1: Fig. S9). In addition, the estimated SDRs were far too smoothed to show the existence of shallow SDRs. These synthetic tests indicated that the SDRs deeper than $\sim 20 \mathrm{~km}$ were reliably estimated; however, we cannot discuss the SDRs at shallow depths.

Most of the subfaults, with SDRs larger than their errors, were located slightly to the south of the islands at depths of $\sim 20$ to $30 \mathrm{~km}$ (Fig. 3c). These SDRs were 
considered to be reliable according to the synthetic tests (Additional file 1: Figs. S7, S8, Text S1). In contrast, the SDRs in the shallow subfaults were rarely resolved (Additional file 1: Fig. S9), so that limited onshore GNSS solely cannot clarify the existence of the SDRs in the shallow plate interface where Nakamura (2009) determined the source model of the 1771 Yaeyama earthquake (Fig. 1a). We confirmed that these characteristics of the spatial distributions of SDRs were common irrespective of the choice of the analysis period (Additional file 1: Fig. S2), fault discretization (Additional file 1: Fig. S3), and selection of data (Additional file 1: Fig. S10, Text S2) used in the inversion.

\section{Discussion}

Figure 4 compares the spatial distributions of SDRs with the epicenters of LFEs (Arai et al. 2016; Nakamura 2017) and the slip rates of cumulative SSEs from July 2010 to February 2013 (Kano et al. 2018b). Notably, our analysis suggests the existence of a large SDR region at depths of $20-25 \mathrm{~km}$ that is complementarily distributed with LFE epicenters on the shallower side and the large slip area of SSE on the deeper side. This may reflect that frictional properties vary with depth along the plate interface, although it is uncertain whether the shallow plate

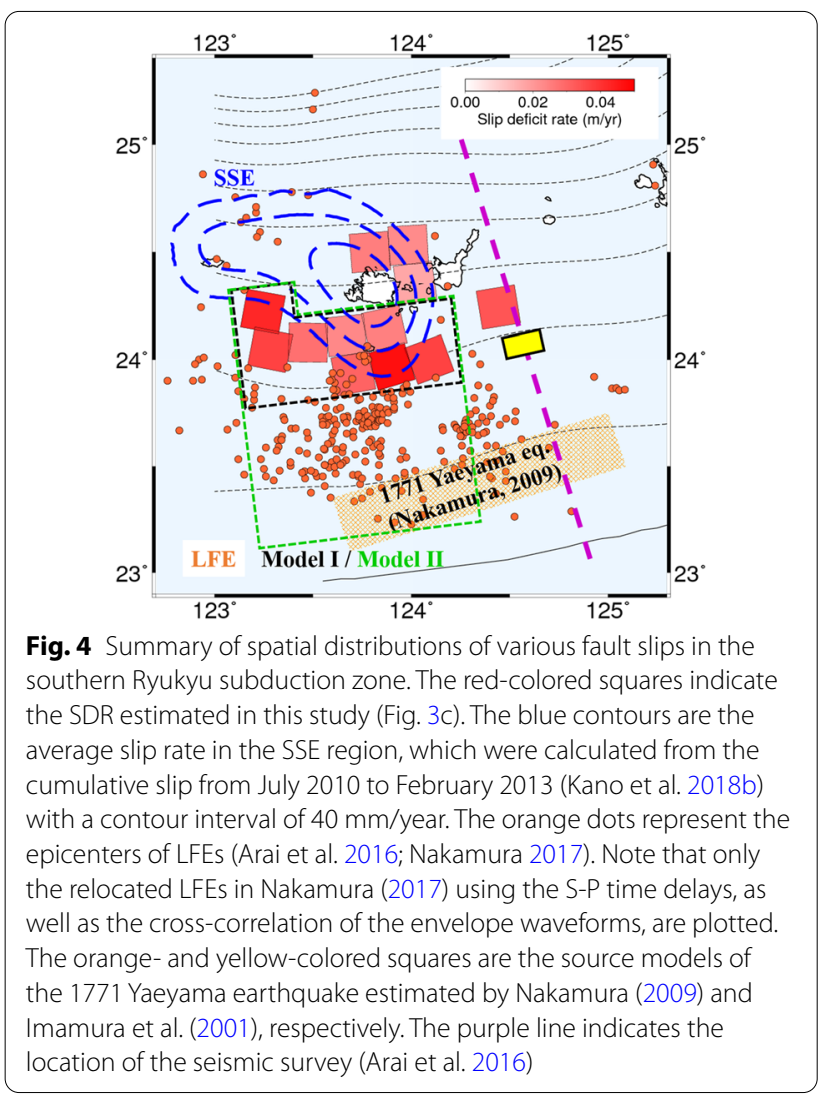

interface where the LFEs occur is coupled or not due to the low resolution (Additional file 1: Fig. S1b). The depth boundary between large SDR and SSE areas was $\sim 25 \mathrm{~km}$, which corresponds to the structural boundary between the crust and mantle wedge in the overriding plate, as investigated by a seismic reflection survey (Figure 3 in Arai et al. 2016); the large SDR areas are located below the arc crust, while the large SSE areas are located below the mantle wedge. Although the profile in the seismic survey (indicated by the purple line in Fig. 4) was located $\sim 50 \mathrm{~km}$ east of Ishigaki Island, the plate geometry does not change significantly in the along-strike direction, and thus, the fault slip style along the plate interface may be related to the structure in the overriding plate. A similar relation between the structure in the overriding plate and fault slip style was indicated by seismic tomography (Yamamoto et al. 2018). Yamamoto et al. (2018) discussed the high $\mathrm{Vp} / \mathrm{Vs}$ of oceanic crust inferred below the SSE region, indicating the existence of fluid that contributes to SSE activities. In addition, their result may suggest an along-dip variation of $\mathrm{Vp} / \mathrm{Vs}$, that is, lower $\mathrm{Vp} / \mathrm{Vs}$ values near the large SDR region compared to the SSE region. However, considering the spatial resolution of tomography ( $30 \mathrm{~km}$ in the horizontal direction), further investigation will be essential to discuss an along-dip variation of the velocity structure and its relation to fault slip style.

Figures $3 \mathrm{a}$ and 4 show small SDRs in the main slip area of the SSEs. As already mentioned, the secular velocities are the long-term average crustal movements that include the effects of both stress release and accumulation in the SSE region. Therefore, small SDRs in the SSE region indicate that the accumulated stress during the inter-SSE period are fully released by the repeated SSEs, as suggested by Kano et al. (2018b).

Our results reliably indicate SDRs of $17-47 \mathrm{~mm}$ /year to the south of the Yaeyama Islands. However, if we consider a $1-\sigma$ estimation error, the SDRs on the significant patches range from 0.09 to $71 \mathrm{~mm} /$ year. In the following discussion, to roughly investigate the magnitude of possible fault slips, we used the representative SDR value of $33 \pm 24 \mathrm{~mm} /$ year calculated by averaging the SDRs for the subfaults to the south of the Yaeyama Islands (the black rectangle in Fig. 4). This value corresponds to $26 \pm 19 \%$ of the relative plate motion $(\sim 13 \mathrm{~cm} /$ year $)$ of the PH relative to the SR. This result indicates that SDRs exist despite the low coupling ratio, suggesting the accumulation of elastic strain for future possible earthquakes.

One possibility to release the slip deficit could be a seismic slip. As there are no records of magnitude 8 class earthquakes around the Yaeyama Islands for the 250 years following 1771 (Ando et al. 2018), it can be stated that if this region accumulates a slip deficit at the same rate in the 2010s analyzed in this study as for the 
250-year period, the expected slip could be $8.4 \pm 6.1 \mathrm{~m}$. If we assume a rigidity of $30 \mathrm{GPa}$ and the source region indicated by the black rectangle in Fig. 4 with a uniform slip of $8.4 \mathrm{~m}$ (we refer to this fault model as model I), this leads to an earthquake with a seismic moment of $8.1 \pm 5.9 \times 10^{20} \mathrm{Nm}$ corresponding to an $\mathrm{Mw}$ of 7.5-8.0. As mentioned before, the resolution of the subfaults shallower than the large SDRs is low (Additional file 1: Fig. S1b), thus it may be possible that the source region extends to shallower depths. If we extend the source region $(\sim 120 \mathrm{~km}$ wide) near the trench axis (we refer to this fault model as model II as indicated in Fig. 4) to reach the location where Nakamura (2009) estimated the source model of the 1771 Yaeyema earthquake, the Mw becomes larger, up to $\sim 8.3$, assuming the same uniform slip as in model I.

Usami (2010) reported from historical documents that Ishigaki Island experienced a ground shaking corresponding to the JMA seismic intensity of IV in the 1771 Yaeyama earthquake as summarized in Ando et al. (2018). Supposing that either models I or II caused this earthquake, both models could result in the large ground shaking in the Ishigaki Island as reported by Usami (2010). Tsunami deposits indicated that the 1771 earthquake generated large tsunamis leading to maximum runups of $\sim 27 \mathrm{~m}$ on the eastern coast of Ishigaki Island (e.g., Ando et al. 2018). As mentioned above, model II includes a part of the source region of Nakamura (2009), which was determined to explain the recorded tsunami heights by numerical simulation. Therefore, model II can generate tsunamis as well although the amplitude of shallow slip needs to be further considered for the quantitative comparison of tsunami run-up heights. On the other hand, model I is unlikely to generate large tsunamis because it is an interplate earthquake at depths of $20-25 \mathrm{~km}$. Thus, a possible scenario to cause such a large tsunami may be that a submarine landslide occurred in addition to the earthquake itself. Imamura et al. (2001) proposed a model in which the submarine landslide triggered by an intraplate earthquake caused the large 1771 tsunami. Although the location of this source model is $\sim 40 \mathrm{~km}$ away from the eastern edge of the large SDR area (indicated by a yellow square in Fig. 4), if the interplate earthquake in model I resulted in a submarine landslide in the same location, the large tsunami run-up height could be explained. Other models of the 1771 tsunami were proposed (Hsu et al. 2013; Okamura et al. 2018). Based on seismic reflection surveys, Hsu et al. (2013) proposed that the tsunami was related to a thrust fault along the $\sim 450 \mathrm{~km}$ long mega-splay fault in the trench parallel direction east of $125.5^{\circ} \mathrm{E}$ close to the Ryukyu Trench. On the other hand, Okamura et al. (2018) discovered a seafloor depression on the seafloor located above the source model of Nakamura (2009). This depression was interpreted to be caused by the collapse of the accretionary prism and the resulting rotational slide. They showed that the collapse can explain the 1771 tsunami regardless of the coupling state of the shallow plate interface. Both models indicated a tsunami source close to the Ryukyu Trench; however, our results cannot judge these possible scenarios, as we only considered the SDRs along the subducting plate interface, and onland GNSS data cannot resolve the coupling of splay faults located close to the trench.

Another possibility through which SDRs are released is by aseismic slip, that is, through SSEs. Although SSEs were recurrently identified with an Mw greater than 6.2, particularly on the deeper side of the large SDR areas (Heki and Kataoka 2008; Nishimura 2014), SSEs including the large SDR region as the source area have not been detected at least since the establishment of GEONET. It may be possible that such a transient slip would occur in the edge of the large SDR region as inferred in the Nankai subduction zone (Kano et al. 2019). Considering the high resolution in the large SDR region, the GNSS observations would be able to detect similar magnitudes of SSEs as those of the deeper ones if an SSE were to occur in the large SDR region. There are three possibilities. One possibility is that quite a large SSE would occur in this region, which has, however, not occurred at least in recent two decades. Supposing that such a large SSE would occur with a recurrence interval of 30 years and release all the slip deficits of $33 \pm 24 \mathrm{~mm} /$ year, the SSE will have a seismic moment of $9.5 \pm 6.9 \times 10^{19} \mathrm{Nm}$, corresponding to an Mw of 6.9-7.4, which would be certainly detected by the GNSS. In this case, the SDRs can be explained by aseismic slip only. However, large SSEs with such a long recurrence interval have not been observed because of a lack of long-term GNSS observations. Therefore, this possibility is less plausible, although we cannot entirely rule it out. The second possibility is that a long-lived SSE with durations longer than a few decades is occurring; however, this would be difficult to identify from recent GNSS observations. The third possibility is that SSEs would have occurred within the large SDR region, but were too small to be detected by the GNSS. However, it would be difficult to explain the large SDR based on such a series of relatively small SSEs. In this case, the large slip deficit would not be released by an aseismic slip alone but seismically. Although the observations, which are limited in both time and space, cannot resolve which of the three possibilities discussed above is true, continuous GNSS observations as well as seafloor geodetic observations will reveal more about the potential of megathrust earthquakes in the southern Ryukyu region. 
Our inversion results indicated significant SDR regions of $17-47 \mathrm{~mm}$ /year that would be possibly released by seismic slip. These SDR values correspond to the low coupling ratio of $13-36 \%$ calculated from the relative plate motion ( $\sim 13 \mathrm{~cm} /$ year) of the $\mathrm{PH}$ relative to the SR. Although these values include estimation errors, they suggest that these regions may mostly show a steady sliding, but occasionally result in a dynamic slip. Numerical simulations on earthquake cycles suggested that constant sliding and dynamic slip will occur in the same fault during complex cycles (e.g., Hori and Miyazaki 2011; Nakata et al. 2012; Noda and Lapusta 2013). For example, Hori and Miyazaki (2011) reported that aseismic stable sliding with a speed of $\sim 34-62 \%$ of the plate subduction rate occurred after a nearby magnitude 7 class earthquake, while the same area indicated a dynamic rupture during a magnitude 9 class earthquake. This complex slip behavior may not be the result of a single source fault but that of a complex interaction between nearby multiple source regions. Although this model is not directly applicable to our study area, coexistence of both fast slip and steady sliding within a low coupling area may imply the existence of another potential seismic source located, for example, in the shallow plate interface or at similar depths on the western or eastern side of the large SDR region revealed in this study. The latter region may be too far from the onshore GNSS stations to investigate plate coupling. Seafloor geodetic observations will be important from this point of view as well.

A possible modification of the proposed SDR model would involve the viscoelastic effect in the asthenosphere, while our modeling is based on the elastic model alone. Ignoring the viscoelastic effect was shown to lead to the overestimation of the lower limit of the locking depth and the amount of SDR (e.g., Li et al. 2015, 2018; Itoh et al. 2021). This is because the viscous relaxation lends itself to a long-wavelength deformation, resulting in movement at more distant stations compared to the elastic model. These results were based on inversion results using secular velocities, while we used distance changes in addition to vertical velocities. Therefore, further analysis is necessary to examine the effect of viscoelasticity on our results. Introducing viscoelasticity is also important while interpreting the temporal variation of vertical velocities. When recurrence intervals of earthquakes are considerably longer than the asthenospheric viscous relaxation time, as in the case of the southern Ryukyu area, decadal-scale temporal variation of interseismic deformation becomes more significant in the later stage of the interseismic period (Sagiya 2015; Hashima and Sato 2017). Hashima and Sato (2017) numerically calculated the vertical deformation associated with the 2011 Tohoku-oki earthquake using a simple two-layered lithosphere-asthenosphere model. Their results indicated that the viscoelastic effect due to coseismic slip is more significant than the effect of interplate locking in the early stage of the interseismic period, while the latter is predominant in the later interseismic period. As a result, temporal variation of vertical velocities at onland stations $>50 \mathrm{~km}$ from the interplate coupling area became more significant. In addition, the spatial pattern of the vertical deformation was different from the assumed slip models whether the coseismic slip reaches the asthenosphere (Hashima and Sato 2017). Therefore, how viscoelasticity affects SDR estimation depends on the assumed model. In any case, continuous monitoring of vertical velocities and their decadal-scale temporal change will lead to a more realistic modeling of interplate coupling with a viscoelastic model. In addition, although we only consider the motion due to plate subduction, viscoelastic effects due to back-arc spreading to the north of the Yaeyama Islands will affect the secular velocities. Therefore, this should be taken into account when considering viscoelasticity, which will be subject to future study.

\section{Conclusion}

We estimated the spatial distributions of SDRs in the southern Ryukyu subduction zone based on GNSS observations during the last 10 years. The inversion results indicated a reliable estimate of $17-47 \mathrm{~mm} /$ year SDRs to the south of the Yaeyama Islands. The large SDR areas are located at depths of 20-25 km, intervened by LFE epicenters on the shallower side and SSE regions on the deeper side of the plate interface. If this region accumulates stress in the same rate as in the recent decade since the last 1771 Yaeyama earthquake, this may result in an Mw of 7.5 or larger megathrust earthquakes. Although limited onshore observations cannot determine whether the large SDR regions extend to the shallow fault region near the trench axis, as estimated by Nakamura (2009), and the true tsunami source in 1771, current geodetic data indicate that the southern side of the Yaeyama Islands has the potential for megathrust earthquakes. Seafloor geodetic observations as well as continuous onland GNSS observations will be essential to reveal more about the earthquake potential in the southern Ryukyu region including the detailed spatial distribution of SDRs especially at shallower depths.

\section{Abbreviations}

PH: Philippine Sea plate; GNSS: Global Navigation Satellite System; SSE: Slow slip event; Mw: Moment magnitude; LFE: Low-frequency earthquake; VLFE: Very low-frequency earthquake; SDR: Slip deficit rate; GEONET: GNSS Earth Observation Network System; GSI: Geospatial Authority of Japan; KT: Kyoto University; KS: Kyushu University; NAOJ: National Astronomical Observatory of 
Japan; ITRF: International Terrestrial Reference Frame; JMA: Japan Meteorological Agency.

\section{Supplementary Information}

The online version contains supplementary material available at https://doi. org/10.1186/s40623-021-01531-z.

\begin{abstract}
Additional file 1: Figure S1. Location of earthquakes considered in the GNSS pre-processing to remove the offsets. Figure S2. Secular velocities and distance changes from January 2015 to February 2021. Figure S3. Estimation of SDR and comparison with observations from January 2015 to February 2021. Figure S4. Results of different fault discretization. Figure S5. Cost function with respect to hyperparameter. Figure S6. Distance changes and vertical velocities calculated from the SDRs at subfaults whose SDRs were greater than their estimation errors. Figure S7. Checkerboard test. Figure $\mathbf{S 8}$. Synthetic tests assuming the SDR region at deep subfaults where large SDRs were estimated. Figure $\mathbf{S 9}$. Synthetic tests assuming the SDRs at shallow subfaults. Figure S10. Effect of data selection. Text S1. Synthetic tests. Text S2. Effect of data selection.
\end{abstract}

\section{Acknowledgements}

We appreciate Takeshi Sagiya, who reviewed and edited the manuscript, and an anonymous reviewer for their fruitful comments to improve the manuscript. Discussion with Ryuta Arai was helpful to interpret the results. Generic Mapping Tools by Wessel and Smith (1998) were used to generate figures. We are grateful to the Jet Propulsion Laboratory for the Gipsy-X software and related GNSS products.

\section{Authors' contributions}

MK, SM, TN designed this study. MK and Al analyzed the GNSS time series to obtain the distance changes. TN pre-processed the GNSS data using the Gipsy-X software. MK conducted inversion analysis and prepared the manuscript. SM, TN, TM developed and maintained the GNSS stations. All authors discussed the results. All authors read and approved the final manuscript.

\section{Funding}

This study was supported by the JSPS KAKENHI Grant Number JP18K03796 and JP21K03694 in Grant-in-Aid for Scientific Research (C). JP16H06474 in Scientific Research on Innovative Areas "Science of Slow Earthquakes", the Ministry of Education, Culture, Sports, Science and Technology (MEXT) of Japan, under its Earthquake and Volcano Hazards Observation and Research Program, and the MEXT Project for Seismology toward Research Innovation with Data of Earthquake (STAR-E) Grant Number JPJ010217.

\section{Availability of data and materials}

The GEONET data can be downloaded from https://terras.gsi.go.jp/ and the GNSS data operated by KT and KS are available by contacting the authors. The GNSS data operated by NAO were provided by Y. Tamura. The catalogs of LFES (Arai et al. 2016; Nakamura 2017) were downloaded from "Slow Earthquake Database" (Kano et al. 2018a; http://www-solid.eps.s.u-tokyo.ac.jp/ sloweq/) supported by JSPS KAKENHI Grant Number JP16H06472 in Scientific Research on Innovative Areas "Science of Slow Earthquakes".

\section{Declarations}

Ethics approval and consent to participate

Not applicable.

\section{Consent for publication}

Not applicable.

\section{Competing interests}

The authors declare that they have no competing interests.

\section{Author details}

'Graduate School of Science, Tohoku University, 6-3, Aramaki-aza-aoba, Aoba-ku, Sendai 980-8578, Japan. ${ }^{2}$ Disaster Prevention Research Institute,
Kyoto University, Gokasho, Uji, Kyoto 611-0011, Japan. ${ }^{3}$ Graduate School of Science, Kyoto University, Kitashirakawa Oiwake-cho, Sakyo-ku, Kyoto 606-8502, Japan. ${ }^{4}$ Institute of Seismology and Volcanology, Faculty of Science, Kyushu University, 2-5643-29 Shin'yama, Shimabara, Nagasaki 855-0843, Japan.

Received: 4 August 2021 Accepted: 17 October 2021

Published online: 26 October 2021

\section{References}

Altamimi Z, Métivier L, Rebischung P, Rouby H, Collilieux X (2017) ITRF2014 plate motion model. Geophys J Int 209(3):1906-1912. https://doi.org/10. 1093/gji/ggx136

Ando M, Nakamura M, Matsumoto T, Furukawa M, Tadokoro K, Furumoto M (2009) Is the Ryukyu subduction zone in Japan coupled or decoupled? The necessity of seafloor crustal deformation observation. Earth Planets Space 61:1031-1039. https://doi.org/10.1186/bf03352954

Ando M, Tu Y, Kumagai H, Yamanaka Y, Lin CH (2012) Very low frequency earthquakes along the Ryukyu subduction zone. Geophys Res Lett 39:L04303. https://doi.org/10.1029/2011GL050559

Ando M, Kitamura A, Tu Y, Ohashi Y, Imai T, Nakamura M, Ikuta R, Miyairi Y, Yokoyama Y, Shishikura M (2018) Source of high tsunamis along the southernmost Ryukyu trench inferred from tsunami stratigraphy. Tectonophysics 722:265-276. https://doi.org/10.1016/j.tecto.2017.11.007

Arai R, Takahashi T, Kodaira S, Kaiho Y, Nakanishi A, Fujie G, Nakamura Y, Yamamoto Y, Ishihara Y, Miura S, Kaneda Y (2016) Structure of tsunamigenic plate boundary and low-frequency earthquakes in the southern Ryukyu trench. Nat Commun 7:12255. https://doi.org/10.1038/ncomms12255

Araoka D, Yokoyama Y, Suzuki A, Goto K, Miyagi K, Miyazawa K, Matsuzaki H, Kawahata H (2013) Tsunami recurrence revealed by Porites coral boulders in the southern Ryukyu Islands, Japan. Geology 41 (8):919-922. https:// doi.org/10.1130/G34415.1

Bertiger W, Bar-Sever Y, Dorsey A, Haines B, Harvey N, Hemberger D, Heflin M, Lu W, Miller M, Moore AW, Murphy D, Ries P, Romans L, Sibois A, Sibthorpe A, Szilagyi B, Vallisneri M, Willis P (2020) GipsyX/RTGX, a new tool set for space geodetic operations and research. Adv Space Res 66(3):469-489. https://doi.org/10.1016/j.asr.2020.04.015

Boehm J, Werl B, Schuh H (2006) Troposphere mapping functions for GPS and very long baseline interferometry from European Centre for MediumRange Weather Forecasts operational analysis data. J Geophys Res. https://doi.org/10.1029/2005JB003629

Fujiwara O, Goto K, Ando R, Garrett E (2020) Paleotsunami research along the Nankai Trough and Ryukyu Trench subduction zones-current achievements and future challenges. Earth-Sci Rev 210:103333. https://doi.org/ 10.1016/i.earscirev.2020.103333

Hashima A, Sato T (2017) A megathrust earthquake cycle model for Northeast Japan: bridging the mismatch between geological uplift and geodetic subsidence. Earth Planets Space 69:23. https://doi.org/10.1186/ s40623-017-0606-6

Hayes GP, Moore GL, Portner DE, Hearne M, Flamme H, Furtney M, Smoczyk GM (2018) Slab2, a comprehensive subduction zone geometry model. Science 362(6410):58-61. https://doi.org/10.1126/science.aat4723

Heki K, Kataoka T (2008) On the biannually repeating slow slip events at the Ryukyu trench, southwestern Japan. J Geophys Res 113:B11402. https:// doi.org/10.1029/2008jb005739

Hori T, Miyazaki S (2011) A possible mechanism of M 9 earthquake generation cycles in the area of repeating M 7-8 earthquakes surrounded by aseismic sliding. Earth Planets Space 63:48. https://doi.org/10.5047/eps. 2011.06.022

Hsu SK, Yeh YC, Sibuet JC, Doo WB, Tsai CH (2013) A mega-splay fault system and tsunami hazard in the southern Ryukyu subduction zone. Earth Planet Sci Lett 362:99-107. https://doi.org/10.1016/j.epsl.2012.11.053 Imamura F, Yoshida Y, Moore A (2001) Numerical study of the 1771 Meiwa tsunami at Ishigaki Island, Okinawa and the movement of the tsunami stones. Proc Coastal Eng Jpn Soc Civ Eng 48:346-350 (in Japanese)

Imamura F, Goto K, Ohkubo S (2008) A numerical model for the transport of a boulder by tsunami. J Geophys Res 113:C01008. https://doi.org/10.1029/ 2007jc004170

Itoh Y, Nishimura T, Wang K, He J (2021) New megathrust locking model for the southern Kurile subduction zone incorporating viscoelastic 
relaxation and non-uniform compliance of upper plate. J Geophys Res 126:e2020JB019981. https://doi.org/10.1029/2020JB019981

Kano M, Aso N, Matsuzawa T, Ide S, Annoura S, Arai R, Baba S, Bostock M, Chao K, Heki K, Itaba S, Ito Y, Kamaya N, Maeda T, Maury J, Nakamura M, Nishimura T, Obana K, Ohta K, Poiata N, Rousset B, Sugioka H, Takagi R, Takahashi T, Takeo A, Tu Y, Uchida N, Yamashita Y, Obara K (2018a) Development of a slow earthquake database. Seis Res Lett 89(4):1566-1575. https://doi.org/10.1785/0220180021

Kano M, Fukuda J, Miyazaki S, Nakamura M (2018b) Spatiotemporal evolution of recurrent slow slip events along the southern Ryukyu subduction zone, Japan, from 2010 to 2013. J Geophys Res Solid Earth. https://doi. org/10.1029/2018JB016072

Kano M, Kato A, Obara K (2019) Episodic tremor and slip silently invades strongly locked megathrust in the Nankai Trough. Sci Rep 9:9270. https:// doi.org/10.1038/s41598-019-45781-0

Kreemer C, Blewitt G, Klein EC (2014) A geodetic plate motion and Global Strain Rate Model. Geochem Geophys Geosyst 15(10):3849-3889. https:// doi.org/10.1002/2014GC005407

Langbein J (2004) Noise in two-color electronic distance meter measurements revisited. J Geophys Res Solid Earth. https://doi.org/10.1029/2003JB0028 19

Langbein J (2017) Improved efficiency of maximum likelihood analysis of time series with temporally correlated errors. J Geod 91 (8):985-994. https:// doi.org/10.1007/s00190-017-1002-5

Li S, Moreno M, Bedford J, Rosenau M, Oncken O (2015) Revisiting viscoelastic effects on interseismic deformation and locking degree: a case study of the Peru-North Chile subduction zone. J Geophys Res Solid Earth 120:4522-4538. https://doi.org/10.1002/2015JB011903

Li S, Wang K, Wang Y, Jiang Y, Dosso SE (2018) Geodetically inferred locking state of the Cascadia megathrust based on a viscoelastic Earth model. J Geophys Res Solid Earth 123:8056-8072. https://doi.org/10.1029/2018J B015620

Lyard FH, Allain DJ, Cancet M, Carrère L, Picot N (2021) FES2014 global ocean tide atlas: design and performance. Ocean Sci 17(3):615-649. https://doi. org/10.5194/os-17-615-2021

Nakamura M (2009) Fault model of the 1771 Yaeyama earthquake along the Ryukyu trench estimated from the devastating tsunami. Geophys Res Lett 36:L19307. https://doi.org/10.1029/2009GL039730

Nakamura M (2017) Distribution of low-frequency earthquakes accompanying the very low frequency earthquakes along the Ryukyu trench. Earth Planets Space 69(1):49. https://doi.org/10.1186/s40623-017-0632-4

Nakamura M, Sunagawa N (2015) Activation of very low frequency earthquakes by slow slip events in the Ryukyu trench. Geophys Res Lett 42:1076-1082. https://doi.org/10.1002/2014gl062929

Nakata R, Hyodo M, Hori T (2012) Numerical simulation of afterslips and slow slip events that occurred in the same area in Hyuga-nada of southwest Japan. Geophys J Int 190(2):1213-1220. https://doi.org/10.1111/j.1365246X.2012.05552.x

Nishimura T (2014) Short-term slow slip events along the Ryukyu trench, southwestern Japan, observed by continuous GNSS. Prog Earth Planet Sci 1(1):22. https://doi.org/10.1186/s40645-014-0022-5
Nishimura S, Hashimoto M, Ando M (2004) A rigid block rotation model for the GPS derived velocity field along the Ryukyu arc. Phys Earth Planet Int 142(3-4):185-203. https://doi.org/10.1016/j.pepi.2003.12.014

Noda H, Lapusta N (2013) Stable creeping fault segments can become destructive as a result of dynamic weakening. Nature 493:518-521. https://doi.org/10.1038/nature11703

Okada Y (1992) Internal deformation due to shear and tensile faults in a halfspace. Bull Seismol Soc Am 82(2):1018-1040

Okamura Y, Nishizawa A, Fujii Y, Yanagisawa H (2018) Accretionary prism collapse: a new hypothesis on the source of the 1771 giant tsunami in the Ryukyu Arc, SW Japan. Sci Rep 8(1):13620. https://doi.org/10.1038/ s41598-018-31956-8

Sagiya T (2015) Paradoxical vertical crustal movement along the Pacific coast of Northeast Japan. Int Assoc Geodesy Symp 145:73-78. https://doi.org/ 10.1007/1345_2015_189

Savage JC (1983) A dislocation model of strain accumulation and release at a subduction zone. J Geophys Res Solid Earth 88(B6):4984-4996. https:// doi.org/10.1029/JB088iB06p04984

Sella GF, Dixon TH, Mao A (2002) REVEL: a model for recent plate velocities from space geodesy. J Geophys Res 107(B4):2081. https://doi.org/10. 1029/2000JB000033

Sibuet JC, Deffontaines B, Hsu SK, Thareau N, Formal JPL, Liu CS, Party ACT (1998) Okinawa trough backarc basin: early tectonic and magmatic evolution. J Geophys Res 103:30245-30267. https://doi.org/10.1029/ 98JB01823

Tu Y, Heki K (2017) Decadal modulation of repeating slow slip event activity in the southwestern Ryukyu Arc possibly driven by rifting episodes at the Okinawa trough. Geophys Res Lett 44(18):9308-9313. https://doi.org/10. 1002/2017GL074455

Usami T (2010) Seismic intensities and isoseismic contours of historical earthquakes in Japan. Japan Electric Association, Tokyo (in Japanese)

Watanabe T, Tabei T (2004) GPS velocity field and seismotectonics of the Ryukyu arc, southwest Japan. J Seismol Soc Jpn 57(1):1-10 ((in Japanese with English abstract)

Wessel P, Smith WHF (1998) New, improved version of Generic Mapping Tools released. EOS Trans AGU 79:579

Yamamoto Y, Takahashi T, Ishihara Y, Kaiho Y, Arai R, Obana K et al (2018) Modeling the geometry of plate boundary and seismic structure in the southern Ryukyu Trench subduction zone, Japan, using amphibious seismic observations. J Geophys Res: Solid Earth 123:1793-1809. https:// doi.org/10.1002/2017JB015330

\section{Publisher's Note}

Springer Nature remains neutral with regard to jurisdictional claims in published maps and institutional affiliations.

\section{Submit your manuscript to a SpringerOpen ${ }^{\odot}$ journal and benefit from:}

- Convenient online submission

- Rigorous peer review

- Open access: articles freely available online

- High visibility within the field

- Retaining the copyright to your article

Submit your next manuscript at $\boldsymbol{\Delta}$ springeropen.com 